\title{
Técnicas e cuidados na aplicação do clareamento dental
}

\author{
Techniques and care in the application of dental whitening
}

Técnicas y cuidados en la aplicación del blanqueamiento dental

Vítor Alexandre Freire Lima ${ }^{1 *}$, Izabel Cristina Gomes de Mendonça.

\begin{abstract}
RESUMO
Objetivo: Descrever as consequências dos agentes que estão presentes nos produtos clareadores aos tecidos dentais e a técnica adequada para sua utilização, visando amenizar a sensibilidade que tantos pacientes demonstram possuir. Revisão bibliográfica: Existem duas técnicas que pode ser utilizada pelo Cirurgião Dentista (CD) para o processo de clareamento dental, sendo elas: o que é feito no consultório odontológico e o caseiro supervisionado com frequência pelos profissionais. $O$ tratamento realizado no consultório odontológico utiliza o peróxido de hidrogênio ou de carbamida em uma concentração mais elevada, quando comparado com o realizado em casa, os procedimentos feitos no consultório o paciente apresenta resultados desejados em menor tempo já que a concentração desses agentes varia de 35 a $40 \%$. Para ser feito um tratamento adequado e individualizado é necessário fazer uma boa anamnese no paciente, buscando saber se existe histórico de sensibilidade, se são fumantes, gestantes, pessoas com lesões précancerígenas e alergias. Considerações finais: $O$ profissional deve ter o cuidado em fazer a técnica correta. Além do mais, com a grande busca por dentes mais brancos, novas pesquisas sobre essa temática estão surgindo, por isso a importância do profissional sempre se atualizar para dar o melhor conforto ao seu paciente.
\end{abstract}

Palavras-chave: Clareamento dental, Odontologia, Clareadores, Sensibilidade da dentina.

\section{ABSTRACT}

Objective: Check the consequences of agents that are present in bleaching products to dental tissues, and the proper technique for their use, aiming to alleviate the sensitivity that so many patients demonstrate to have right after their application. Bibliographic review: There are two techniques that can be used by the Dental Surgeon (CD) for the tooth whitening process, namely: what is done in the dental office and the homemade one, frequently supervised by professionals. The treatment carried out in the dental office uses hydrogen peroxide or carbamide in a higher concentration, when compared to that carried out at home, the procedures performed in the patient's office present desired results in less time since the concentration of these agents varies from 35 to $40 \%$. In order to provide an adequate and individualized treatment, it is necessary to take a good anamnesis in the patient, trying to find out if there is a history of sensitivity, if they are smokers, pregnant women, people with pre-cancerous lesions and allergies. Final considerations: The professional must be careful in using the correct technique. Furthermore, with the great search for whiter teeth, new research on this topic is emerging, which is why it is important for professionals to always update themselves in order to provide the best comfort for their patients.

Keywords: Tooth bleaching, Dentistry, Bleaching agents, Dentin sensitivity.

\section{RESUMEN}

Objetivo: Describir las consecuencias de los agentes presentes en los productos blanqueadores sobre los tejidos dentales y la técnica adecuada para su uso, con el objetivo de paliar la sensibilidad que tantos pacientes demuestran. Revisión bibliográfica: Hay dos técnicas que puede utilizar el Cirujano Dentista (CD) para el proceso de blanqueamiento dental, a saber: la que se realiza en el consultorio dental y la casera, frecuentemente supervisada por profesionales. El tratamiento realizado en el consultorio odontológico utiliza peróxido de hidrógeno o carbamida en una concentración mayor, al compararlo con el realizado en el hogar, los procedimientos realizados en el consultorio odontológico presentan los resultados deseados en menos tiempo ya que la concentración de estos agentes varía de 35 a $40 \%$. Para poder brindar un tratamiento adecuado e individualizado, es necesario realizar una buena anamnesis en el paciente, tratando de averiguar si hay antecedentes de sensibilidad, si son fumadores, embarazadas, personas con lesiones precancerosas y alergias. Consideraciones finales: El profesional debe tener cuidado al utilizar la técnica correcta. Además, con la gran búsqueda de dientes más blancos, están surgiendo nuevas investigaciones sobre este tema, por lo que es importante que los profesionales se actualicen siempre para brindar el mejor confort a sus pacientes.

Palabras clave: Blanqueamiento de dientes, Odontología, Blanqueadores, Sensibilidad de la dentina.

${ }^{1}$ Centro Universitário CESMAC (CESMAC), Maceió - AL. *E-mail: vitorfreireodonto@outlook.com

SUBMETIDO EM: 11/2021

ACEITO EM: 12/2021

PUBLICADO EM: 12/2021 


\section{INTRODUÇÃO}

A grande busca por um sorriso excelente implantado pelos novos padrões de estéticas faciais como sendo um sinônimo de beleza, está fazendo com que cada vez mais os pacientes busquem os Cirurgiões Dentistas (CD), visando dentes não só mais harmônicos, como também mais claros. As pesquisas abrangendo a odontológica nos dias atuais não têm apenas se sensibilizado com problemas patológicos que correspondem a cavidade bucal, notando-se uma propensão cada vez mais por pesquisas com amplitudes voltadas para a cosmética, tendo como objetivo agradar os anseios da população, visto que esse fator possui um grande impacto na autoestima das pessoas que procuram por esses procedimentos (BARBOSA DC, et al., 2015).

Essa imensa procura por parte dos pacientes tem feito com que ocorra uma maior expansão nas técnicas utilizadas pelos CDs e os produtos utilizados para o procedimento, a fim de melhorar e aprimorar cada vez mais os agentes clareadores com o intuito de obter resultados mais precisos e rápidos, levando sempre em consideração os cuidados para manter os elementos dentais saudáveis (CASADO BGS, et al., 2018).

O clareamento dental vem sendo praticado há várias décadas pelos CDs, existem relatos que na década de 80 já utilizavam agentes oxidantes instáveis com o propósito de deixar mais claros os dentes que eram mais escuros que os normais. Popularizando-se mais no ano de 1990, quando se utilizavam moldeiras feitas por moldagens individualizadas para clareamento dos dentes vitais elucidado por Haywood e Heymann, no entanto essa técnica, denominada clareamento caseiro, não é indicada para solucionar todos os casos de dentes escurecidos, sendo imprescindível a utilização de outras técnicas, como é o caso da técnica usada no consultório odontológico (MATIS BA, et al., 2015).

Um dos motivos para essa escolha está relacionado com as causas que levam à modificação de tonalidade dos dentes e como esse escurecimento pode prejudicar a aparência dos mesmos. As causas são muitas e variadas, e são classificadas como extrínsecas ou intrínsecas (CASADO BGS, et al., 2018). As pigmentações ocasionadas de maneira extrínseca geralmente são acometidas devido a aglomeração de bactérias cromogênicas que grudam nas ondulações ou defeitos presentes na parte mais superficial do dente, esse acúmulo é associado na maioria das vezes à má higienização oral, a dieta do paciente e ao uso de tabaco (REINHARDT JW, et al., 2019).

Quando se trata das modificações intrínsecas observa-se que são na maioria das vezes provocadas por manchas na parte mais profunda, no interior dos dentes ou ocasionadas por alguns defeitos presentes no esmalte, como é o caso da hipormineralização, problemas relacionados a idade do paciente, uso de fármacos como é o caso da tetraciclina, excesso de flúor, problemas sanguíneos como nos pacientes portadores de icterícia grave, dentes que foram submetidos a tratamentos endodônticos e trauma (CAREY CM, 2014).

Nos dias atuais, utiliza-se duas técnicas para a aplicação do clareamento nos dentes vitais, a primeira é a caseira, como o nome já diz, é feita em casa, mas com o acompanhamento do paciente pelo profissional responsável, enquanto a segunda é estabelecida no consultório odontológico feita exclusivamente pelos CDs (MATIS BA, et al., 2015). Contudo, vale ressaltar, que o CD em primeiro lugar, deve realizar uma boa anamnese para saber o histórico do paciente, para só assim entender os possíveis fundamentos que provocaram essa modificação da tonalidade dos elementos dentais, isto posto, é realizado o protocolo que irá ser implantado (BRENNAN MM, et al., 2014; REINHARDT JW, et al., 2019).

Pelo fato dessas duas técnicas possuírem como seus princípios ativos o peróxido de carbamida e o peróxido de hidrogênio, faz com quer ocorra inúmeros casos de pacientes que se queixam de sensibilidade logo após o procedimento, além de outros casos de irritabilidade na mucosa que circunda os elementos dentais, entre outros fatores observados, como a deterioração da parte marginal na linha de união entre 0 dente e a restauração (PASQUALI EL, et al., 2014).

Em virtude da larga quantidade de público em busca desse procedimento executado pelos CDs, inúmeras pesquisas não esclarecedoras enquadram suas metodologias e as inúmeras aplicações de maneira exagerada e por sua vez desconforme, o objetivo do trabalho foi verificar por meio de uma revisão de literatura, as consequências dos agentes que estão presentes nos produtos clareadores aos tecidos dentais, e a técnica adequada para sua utilização, visando dessa maneira amenizar a sensibilidade que tantos pacientes demonstram possuir logo após sua aplicação. 


\section{REVISÃO BIBLIOGRÁFICA}

\section{Formação do esmalte}

Para poder saber os feitos do clareamento nos elementos dentais é necessário primeiramente saber como é constituído o esmalte do dente. Sabe-se que o esmalte apresenta seu desenvolvimento no período de amelogênese, tendo por sua vez origem ectodérmica, e revestem a porção coronária dos dentes. Sua forma de consistência é variável, podendo chegar a $2,5 \mathrm{~mm}$ nas regiões de maior trabalho onde apresentam uma linha mais volumosa (FIORILLO L, et al., 2019).

O esmalte dentário é o tecido mais mineralizado, possuindo uma complexa matriz de colágenos e cristais de hidroxiapatita, presente no corpo humano, os compostos de cristais inorgânicos como é o caso do fosfato de cálcio e hidroxiapatita correspondem a $96 \%$ da sua composição, enquanto $3 \%$ é constituído por água e $1 \%$ de matrizes orgânicas. O material orgânico é constituído por polipeptídio que ajuda nas ligações dos aminoácidos para formação das suas estruturas amelogeninas que é uma proteína produzida pelos ameloblastos durante o desenvolvimento do esmalte dentário e proteínas sem produção de colágenos, que estão presentes na parte interprismática (MENDES M, et al., 2017).

A constituição presente no esmalte dental é um processo complexo, no entanto é bem ordenado e controlado por células presentes no epitélio, os ameloblastos, apresentam suma importância no desenvolvimento da codificação das proteínas e são essenciais para a constituição do esmalte. A amelogênese tem início na etapa de formação da coroa do dente e consiste fundamentalmente de duas etapas: a primeira é no período em que ocorre a secreção, nas quais os ameloblastos instituem o esmalte relativamente mineralizado, e a segunda etapa é a que corresponde a maturação, que significa a deposição de mineral, remoção da matéria orgânica e subsequentemente da água presente (PINHEIRO HB. et al., 2011; FIORILLO L, et al., 2019).

O esmalte caracteriza-se por mostrar forte resistência mecânica, sendo capaz de se modificar através do processo de desmineralização provocada por agentes com o potencial hidrogeniônico $(\mathrm{pH})$ mais ácido e atividades de ionização presentes na cavidade oral. As apatitas presentes nos elementos dentais resistem de maneira distinta ao que se refere às mudanças do pH na cavidade oral (TAM LE, et al., 2017).

$\mathrm{Na}$ hidroxiapatita, o $\mathrm{pH}$ crítico é em torno de 5,5, enquanto que a fluorapatita, que é uma variante do mineral hidroxiapatita, apresenta mais resistência aos ácidos, a separação desse mineral é iniciada com o pH menor que 4,5; já a apatita carbonatada induzida provavelmente por modificações estruturais ocorridas na célula unitária por causa das trocas aniônicas, é considerada como sendo a mais vulnerável ao processo de desmineralização ácida, decorrendo em pH menor que 6,5. Assim sendo, distintas áreas presentes no mesmo elemento dental mineralizado respondem de maneiras distintas quando sofre exposição ao meio ácido (FEKRAZAD R, et al., 2017).

O rompimento que ocorre no tecido que compõe o esmalte ocasionada de maneira química, mais conhecido como o processo de desmineralização do esmalte do elemento dental, ocorre através de duas maneiras: a quebra de partículas pelos ácidos presentes nos agentes bacterianos, no qual é estabelecido a cárie dental, e a dissolução provocada por agentes químicos que apresentam ácido em sua constituição, caracterizados por estimular a erosão do dente (TAO D, et al., 2017).

Mesmo sabendo que se trata de um tecido altamente mineralizado, o esmalte mostra certa capacidade para transmitir fluidos para outros tecidos próximos, fazendo com que ocorra a difusão molecular de substâncias e a transferência de íons com a cavidade oral. É esse fator realizado por membranas semipermeáveis que possibilitam o mecanismo do clareamento dental (MORETTI LCT, et al., 2017).

O clareamento dental acontece mediante a decorrência de uma profunda inter-relação de maneira física e química através dos elementos dentais e os agentes causadores do escurecimento do dente. Pinto MM, et al. (2017), ressalta que as técnicas de clareamento utilizadas nos dias de hoje são eficazes e bastante seguras, sendo acompanhadas por um responsável técnico, no entanto, segundo Mileski T, et al. (2018), várias incertezas, até então, são apontadas ao que se refere aos resultados inesperados, ocasionados pelos agentes químicos que são à base de peróxidos, empregados para a retirada de manchas intrínsecas dos elementos dentais. 


\section{Clareamento Externo}

O clareamento externo é destinado a elementos dentais que apresentam vitalidade nos quais o escurecimento pode estar relacionado à idade, a possíveis lesões ou traumas, ou até mesmo à dieta do paciente. Esse processo terapêutico é contraindicado nos casos dos pacientes que possuem hipersensibilidade, alguma anormalidade como é o caso da hipoplasia do esmalte, em gestantes, em indivíduos que têm alergias aos agentes clareadores e crianças com idade inferior a 10 anos, devido ao tamanho da câmara pulpar que ainda está em formação (MENDES M, et al., 2017).

O clareamento dentário externo proporciona um grau de aspecto mais branco e ágil, além do que amplia de forma significativa a autoestima dos pacientes por apresentarem os elementos dentais mais agradáveis esteticamente. No entanto, expõe certos inconvenientes como é o caso de alergias, fato que normalmente não é informado aos pacientes, e irritações na mucosa pois o agente possui em seus componentes o peróxido que pode causar irritações na mucosa oral que dura até 3 dias, outro fator que é válido observar é a quantidade de indivíduos que se queixa da sensibilidade durante e após o procedimento, que varia de alguns dias ou até mesmo podendo ser duradouro (DEMARCO FF, et al., 2016).

Vale ressaltar que o clareamento dental não é definitivo, o tempo de durabilidade dele irá depender de inúmeros fatores como é o caso da dieta do paciente, existe também uma limitação no tempo indicado para ser realizado um outro clareamento, visto que ocorre um processo de desgaste do esmalte acarretando assim maior chance de conferir, além de sensibilidade, maior porosidade ao elemento dental. Essa forma mais porosa, além de inferir uma tonalidade amarelada dos dentes, concedem maior fragilidade podendo provocar com maior chance casos de trincas e até mesmo fraturas (FIORILLO L, et al., 2019).

Quando o paciente chega ao consultório odontológico querendo fazer o clareamento dental, é necessário que o CD faça uma anamnese, tendo em vista que primeiramente é importantíssimo observar o estado geral da cavidade bucal, se há prevalência de caries, doenças periodontais e realizar o plano de tratamento para só então iniciar o clareamento dental (MENDES M, et al., 2017).

\section{Técnicas para o clareamento de dentes vitais}

Existe duas técnicas que podem ser utilizadas pelos CDs para o processo de clareamento dental, sendo eles: o que é feito no consultório odontológico e o caseiro supervisionado com frequência pelos profissionais. O tratamento realizado no consultório odontológico utiliza o peróxido de hidrogênio ou de carbamida em uma concentração mais elevada, quando comparado com o realizado em casa. Nos procedimentos feitos no consultório o paciente apresenta resultados desejados em menor tempo já que a concentração desses agentes varia de 35 a 40\% (GREENWALL-COHEN J, et al., 2018).

Para ser feito um tratamento adequado e individualizado de um paciente para outro é imprescindível a realização de uma boa anamnese no paciente, buscando saber se existe histórico de sensibilidade, se são fumantes, gestantes, presença de lesões pré-cancerígenas e alergias. O tratamento no consultório é sem sombra de dúvidas o mais procurado pelos pacientes, visto que em uma ou duas sessões pode-se alcançar o resultado desejado. No entanto, existem casos onde se faz necessário realizar até 6 sessões para obter um resultado melhor, tendo que ser respeitado um período de 7 dias de uma sessão para outra. Esse tratamento torna-se mais caro por conta do tempo que é gasto no consultório e do tempo que o profissional leva (MAIA TS, et al., 2015).

Quando o paciente e o profissional opta por fazer o tratamento caseiro, o tratamento é realizado exclusivamente pelo próprio paciente e é tido como sendo uma técnica de menor valor financeiro, quando comparado ao do consultório, isso ocorre porque além do tratamento ser feito em casa, o profissional precisa apenas de uma sessão para fazer a moldagem da arcada dentária do paciente e entregar a moldeira individual, os agentes clareadores utilizados são os mesmos da técnica do consultório, porém, a concentração do peróxido de hidrogênio é de 3,6\% visando por sua vez reduzir a possibilidade de iatrogenias, dependendo do paciente opta-se por utilizar carbamida na concentração de 16 a 22\%, nessa mesma sessão o profissional mostra todos os passos e orientações de como deve ser feito a aplicação em casa, e faz um agendamento dos retornos do paciente para que possa acompanhar todo o processo e avaliar o resultado do tratamento (MENDES M, et al., 2017). 


\section{Fatores clínicos}

A mudança da coloração dos elementos dentais pode ser determinada por fatores extrínsecos, como é o caso da dieta rica em corantes, hábito de fumar, a assiduidade da presença de placa bacteriana e uso de alguns fármacos. Entretanto não se limita apenas a esses fatores, como também as causas intrínsecas, como é o caso de hemorragias pulpares por trauma, uso de agentes bacteriostáticos de largo espectro como é o caso da tetraciclina principalmente na fase de gravidez e da infância, entre outras causas (BARBOSA DC, et al., 2015).

Nas causas intrínsecas é realizado o clareamento dos dentes que não apresentam mais vitalidades de maneira interna, quando eles apresentam tratamento endodôntico, o procedimento é feito de forma direta na câmara pulpar, com a seleção de uma das 3 técnicas para esses eventuais procedimentos: mediata quando observa que o dente pode ou está com outra coloração, imediata logo após o tratamento endodôntico, como forma preventiva e mista. É preciso destacar que o prognóstico desse processo terapêutico irá depender do fator causal, os melhores resultados são estabelecidos quando a mancha do dente é provocada por fatores hemorrágicos da polpa ou provocada pelo tecido circundante, enquanto que o escurecimento provocado pela impregnação de sais ou materiais metálicos nos tecidos do dente, como é o caso da restauração feita com amálgama, tem um prognóstico menos favorável (CASADO BGS, et al., 2018).

Para a execução do processo clareador intra-coronário é indispensável o estabelecimento de um tampão ou barreira na parte mais cervical do dente e na entrada do canal radicular, evitando assim a disseminação dos agentes clareadores para a superfície externa do dente, com o intuito de prevenir a invasão do periodonto fato que pode provocar a inflamação no periodonto de proteção e reabsorções externas na raiz do dente. Para ser eficaz, o tampão deve ter de 2 a $3 \mathrm{~mm}$ de um material obturador que pode ser a resina composta e o ionômero de vidro aplicados no acesso do canal radicular. Quando se opta pela utilização da técnica imediata, utiliza-se o peróxido de hidrogênio na proporção de 35-38\% que irá se manter na câmara pulpar apenas no período de tratamento, sendo aplicado na parte vestibular do elemento dental que está sendo tratado (MENDES M, et al., 2017).

Quando o CD faz a escolha da técnica mediata, dispõe do benefício de obter menor tempo no tratamento clínico, nessa técnica, o material utilizado é o perborato de sódio diluído com água destilada o qual é introduzido na câmara pulpar, que é selada e onde o material ficará confinado por 3 dias, sendo recolocado posteriormente por mais 3 sessões clinicas. Já a técnica mista é feita pela unificação das técnicas mediata e imediata, no entanto, o CD deve fazer o acompanhamento do elemento dental com maior frequência, visto que após o clareamento dental é irreversível a coloração final (BRENNAN, MM, et al., 2014; MATIS BA, et al., 2015).

Na ocasião em que as estruturas do esmalte dental são expostas aos compósitos ácidos, os íons presentes de hidrogênio aceleradamente diluem a parte que é mineral, ocasionando a diminuição de íons cálcio e fósforo, fato que resulta na redução dos volumes dos cristais, ocorrendo subsequentemente a dilatação das áreas inter cristalinas. No decurso da dissolução dos agentes, o carbonato que está exposto na ordenação do esmalte também, pode deixar de existir, surgindo a constituição de áreas vazias que se unem podendo prejudicar as proteínas existentes nos cristais (JOINER A e LUO W, 2017).

\section{Sensibilidade}

Cerca de $70 \%$ dos pacientes queixam-se de sensibilidade dentária durante ou logo após o tratamento. Quando o clareamento é feito de forma caseira a sensibilidade é menor e mais suportável, isso porque a concentração do princípio ativo é bastante inferior à que é utilizada no consultório, essa sintomatologia pode desaparecer depois de alguns dias quando o tratamento é concluído. A manifestação da sensibilidade ocorre tanto com alimentos frios ou quente e sem a presença de agentes causais patológicos ou até mesmo má formação dentária. A teoria mais aceita nos dias de hoje é a de Brännström, que sustenta que a sensibilidade provocada por agentes clareadores se fundamenta na transferência e movimentações dos fluidos nos interiores dos túbulos dentinários, promovendo a estimulação das fibras nervosas as quais respondem ao estímulo com dor (PINTO MM, et al., 2017). 
Pesquisas feitas sugerem a indicação de anti-inflamatórios logo após o fim do tratamento realizado, com o objetivo de minimizar a sensibilidade dolorosa, entretanto, outros estudos falam sobre a aplicação da arginina vigente na composição de antissépticos bucais os quais possuem a capacidade de dessensibilizar os elementos dentais. Os dessensibilizantes podem ser utilizados antes do tratamento, já para ir preparando o local onde irá ocorrer o clareamento, no entanto pode ser utilizado durante e depois do tratamento. Outras alternativas também são indicadas aos pacientes pelo CD como é o caso de chicletes sem presença de açúcar, assim como os fármacos fitoterápicos, aplicação de flúor concentrado e a técnica de escovação (FEKRAZAD R, et al., 2017; SOETEMAN GD, et al., 2018).

\section{CONSIDERAÇÕES FINAIS}

Diante do exposto pode-se ressaltar que o tratamento indicado para o clareamento dental deve ser empregado com bastante cautela. Não tendo um padrão geral para todos os pacientes, ela irá ser feita de maneira particularizada, para isso é necessário a presença do $C D$, seja efetivando a técnica ou até mesmo informando ao paciente sobre como utilizar. Sabendo que os agentes clareadores podem provocar, além de inflamações nos tecidos moles, grande sensibilidade dentária ou até mesmo reabsorções ósseas e/ou dentárias, o profissional deve ter o cuidado em fazer a técnica com precisão e tomando todos os cuidados necessários no sentido de evita-los ao máximo. Além do mais, com a grande busca por dentes mais brancos, novas pesquisas sobre essa temática estão surgindo, por isso a importância do profissional sempre se atualizar para dar o melhor conforto ao seu paciente.

\section{REFERÊNCIAS}

1. BARBOSA DC, et al. Estudo Comparativo Entre As Técnicas De Clareamento Dental Em Consultório E Clareamento Dental Caseiro Supervisionado Em Dentes Vitais: Uma Revisão De Literatura. Rev. Odontol. Univ. Cid, São Paulo, 2015; 3: 244-252.

2. BRENNAN MM, et al. Home-use whitening toothpastes for whitening teeth in adults (protocol). Cochrane Libr, 2014; 1: 1-10.

3. CAREY CM. Tooth whitening: what we now know. J Evid Based Dent Pract. 2014; 14(Suppl): 70-77.

4. CASADO BGS, et al. Efficacy of dental bleaching with whitening dentifrices: A systematic review. International Journal of Dentistry, 2018; 2018.

5. DEMARCO FF, et al. Produtos de autocuidado para clareamento dental Self-care products for tooth whitening. RFO, Passo Fundo,2016, 9(1): 143-149.

6. FEKRAZAD R, et al. Comparison of laser and power bleaching techniques in tooth color change. Journal of Clinical and Experimental Dentistry, 2017; 9(4): 511-515.

7. FIORILLO L, et al. Dental Whitening Gels: Strengths and Weaknesses of an Increasingly Used Method. Gels, 2019; 5(3): 35.

8. GREENWALL-COHEN J, et al. Tooth whitening for the under-18-year-old patient. British Dental Journal, 2018; 225(1): 19-26.

9. JOINER A, LUO W. Tooth colour and whiteness: A review. [s.I.] Elsevier Ltd, 2017;67 (2): 22-34.

10. MAIA TS, et al. Harmonização do sorriso com facetas diretas em resina composta: relato de caso. Clín. int. j. braz. dent, 2015; 11(4): 392-401.

11. MATIS BA, et al. White diet: is it necessary during tooth whitening? Oper Dent. 2015; 40(3): 235-40.

12. MENDES M, et al. Clareamento Dental. Revista Científica Faesa, Vitória-ES, 2017; 13(1): $37-42$.

13. MILESKI T, et al. Clareamento interno em dente traumatiazado: relato de caso clínico. Rev. UNINGÁ, Maringá. 2018; 55(2): 24-32.

14. MORETTI LCT, et al. Clareamento de dentes despolpados: relato de um caso clínico. Rev. Arch Health Invest. 2017; 6(5): 213-217.

15. PASQUALI EL, et al. Estudos do Clareamento dental sobre o esmalte:Uma indicação das evidências; Erechim-RS; 2014 (38): 99-108.

16. PINHEIRO HB, et al. Análise microestrutural do esmalte tratado com peróxido de hidrogênio e carbamida. Revista Gaúcha de Odontologia, Porto Alegre, 2011; 59(2): 215-220.

17. PINTO MM, et al. Controlled clinical trial addressing teeth whitening with hydrogen peroxide in adolescents: A 12 month follow-up. Clinics, 2017; 72(5): 161-170.

18. REINHARDT JW, et al. Effect of tooth-whitening procedures on stained composite resins. Operative Dentistry, 2019; 44(1): 65-75.

19. SOETEMAN GD, et al. Whitening dentifrice and tooth surface discoloration a systematic review and meta-analysis. International Journal of Dental Hygiene, 2018; 16(1): 24-35.

20. TAM LE, et al. Effect of tooth whitening strips on fatigue resistance and flexural strength of bovine dentin in vitro. PLoS ONE, 2017; 12(3): 1-11.

21. TAO D, et al. Tooth whitening evaluation of blue covarine containing toothpastes. Journal of Dentistry, 2017; 67: 2024. 